\title{
A Faixa de Dobramento Paraguai na Serra da Bodoquena e Depressão do Rio Miranda, Mato Grosso do Sul
}

\author{
The Paraguay Fold Belt in the Serra da Bodoquena and Miranda River Depression, \\ Mato Grosso do Sul
}

\author{
Ginaldo Ademar da Cruz Campanha1 (ginaldo@usp.br), Paulo César Boggiani² (boggiani@usp.br), \\ William Sallun Filho 3 (wsallun@gmail.com), Fernanda Rostirola de Sá ${ }^{4}$ (fe_rostirola@uol.com.br), \\ Mariana de Paula Souza Zuquim (mariana.zuquim@gmail.com), Thiago Piacentini ${ }^{5}$ (t.piacentini@ uq.edu.au) \\ ${ }^{1}$ Departamento de Mineralogia e G eotectônica - Instituto de Geociências - USP \\ R. do Lago 562, CEP 05508-080, São Paulo, SP, BR \\ ${ }^{2}$ Departamento de Geologia Sedimentar e Ambiental - Instituto de G eociências - USP, São Paulo, SP, BR \\ 3Instituto G eológico - SMASP, São Paulo, SP, BR \\ ${ }^{4}$ Petrobras - Petróleo Brasileiro S.A., Rio de Janeiro, RJ, BR \\ ${ }^{5} \mathrm{School}$ of Earth Sciences - University of Q ueensland, Brisbane, AU
}

Recebido em 02 de dezembro de 2010; aceito em 19 de setembro de 2011

\section{RESUMO}

A Faixa Paraguai meridional evoluiu como um típico fold-and-thrust belt. Sua evolução principia por rifteamento, provavelmente no final do Criogeniano, evoluindo para mar restrito e transgressão marinha extensiva até o final do Ediacarano. O final do processo colisional ocorreu no início do Cambriano, com magmatismo pós-colisional no Cambriano Superior. O Grupo Corumbá é subdividido em cinco formações (Cadiueus, Cerradinho, Bocaina, Tamengo e Guaicurus), estratigrafia esta observada até nas porções mais deformadas no centro-leste da área. A Formação Puga é colocada como correlata às suas formações basais, Cerradinho e Cadiueus. No extremo oeste da área, o Grupo Corumbá está depositado em inconformidade sobre o bloco cratônico Rio Apa. Para os xistos do extremo leste da área, é proposto o nome local Xistos Agachi. Durante o Ediacarano, sincronicamente com a deformação, granitogênese de arco e metamorfismo do Grupo Cuiabá a leste, ter-se-ia a deposição das formações Tamengo e Guaicurus a oeste, provavelmente num contexto de bacia de antepaís (foreland). São observadas até três fases de dobramento sobrepostas coaxiais, associadas a metamorfismo de fácies xisto-verde e sistemas de falhas de empurrão, com vergência tectônica para oeste. A convergência colisional em direção ao bloco Rio Apa não foi completamente frontal, existindo algum grau de obliquidade, com vetores de convergência em torno de WNW-ESE. A variação do estilo estrutural e metamórfico pode ser explicada pela migração do front deformacional de leste para oeste. As principais falhas de empurrão coincidem com limites bacinais importantes, sugerindo que estes empurrões reativaram falhas lístricas do estágio rifte.

Palavras-chave: Brasiliano; Faixa móvel; Grupo Corumbá; Grupo Cuiabá; Neoproterozoico; Ediacarano.

\begin{abstract}
The Southern Paraguay Belt is a typical fold-and-thrust belt. Its geological evolution began with a continental rifting process, probably at the end of the Cryogenian, evolving into a restricted sea and an extensive marine transgression at the end of the Ediacaran. The final collisional event occurred during the Lower Cambrian, with post-collisional magmatism during the Upper Cambrian. The Corumbá Group is divided into five formations (Cadiueus, Cerradinho, Bocaina, Tamengo and Guaicurus). The Puga Formation is correlated to the Cerradinho and Cadiueus formations. This stratigraphy can be seen even in the most deformed parts located in central-eastern area. In the far west of the area, the Corumbá Group is deposited above an unconformity in the Rio Apa cratonic block. The name Agachi Schists is suggested for the schists located at the easternmost portion of the area. During the Ediacaran period, whereas, in the east part of the area, the Cuiabá Group was affected by deformation, metamorphism and arc-related granites, in the west part of the area, the Tamengo and Guaicurus
\end{abstract}


formations were deposited, probably in a context of foreland basin. Up to three superimposed coaxial folding events are observed associated with greenschist metamorphism and thrust faults, showing a westward tectonic vergence. WSW - ESE convergence vectors indicate that the collision with the Rio Apa block was slightly oblique. Changes in metamorphism and structural style can be explained by the westward migration of the deformational front. The main thrust faults coincide with important basin boundaries, suggesting that the listric faults of the rift stage were reactived by them.

Keywords: Brasiliano; Mobile belt; Corumbá Group; Cuiabá Group; Neoproterozoic; Ediacaran.

\section{INTRODUÇÃO}

A Faixa Paraguai constitui unidade geotectônica de destaque na porção oeste da Província Tocantins. Situa-se na borda sul do Cráton Amazônico e a leste do bloco cratônico do Rio Apa, formando um arco com a convexidade voltada para os núcleos cratônicos (Figura 1). Esta faixa tem comprimento aproximado de $1.000 \mathrm{~km}$ e caracteriza-se por intensa deformação linear polifásica, longos falhamentos inversos e/ou empurrão, escassez de produtos vulcânicos expostos e ocorrência de plútons graníticos nas áreas mais internas (Almeida, 1984).

Encontra-se exposta em duas grandes regiões, a porção setentrional, em Mato Grosso, e a porção meridional, aflorante na Serra da Bodoquena e maciço de Urucum (Corumbá), em Mato Grosso do Sul. Essas áreas encontram-se separadas pelas coberturas sedimentares da Bacia do Paraná (paleozoica e mesozoica) e da Bacia do Pantanal (cenozoica).

Trabalhos de análise estrutural são escassos na porção meridional da Faixa Paraguai. Destaca-se o trabalho clássico de Almeida (1965), em escala de reconhecimento da geologia da Serra da Bodoquena. Mapeamentos geológicos sistemáticos foram realizados na década de 1970 (Corrêa et al., 1976, 1979; Nogueira et al., 1978), destacando-se o de Nogueira et al. (op. cit.) os quais apresentam mapeamento na escala 1:50.000 de toda a região estudada no presente trabalho. Compilações em escala regional têm sido apresentadas mais recentemente (Godói, 2001; Lacerda Filho et al., 2006). Estudos estruturais têm sido mais comuns na porção setentrional da Faixa (e.g., Alvarenga, 1990; Alvarenga e Trompette, 1993).

Com base em perfis de campo, análise estrutural e petrográfica, e na integração de um conjunto de dados inéditos em teses, dissertações e monografias (Boggiani, 1990, 1998; Piacentini, 2008; Sá, 2005, 2009; Sallun Filho, 2005; Zuquim, 2005) buscou-se no presente trabalho compor um quadro geológico-estrutural da Faixa Paraguai meridional e compreender as relações estratigráficas entre os litotipos dos grupos Corumbá e Cuiabá e da Formação Puga.

Para tal estudou-se uma ampla região em Mato Grosso do Sul, balizada aproximadamente a oeste pelas escarpas da Serra da Bodoquena e a leste pela serra de Maracaju, a norte pelas localidades de Morraria do Sul, Bodoquena, Miranda e Aquidauana, e a sul pelas localidades de Baía das Garças e Bonito.

A integração geológico - estrutural realizada permitiu a delimitação em mapa das unidades litoestratigráficas ao nível de formação. A Figura 2 mostra os principais traços dessa integração numa escala reduzida e a Figura 3 perfis geológicos com as principais relações estruturais e litoestratigráficas da região estudada. A representação cartográfica ao nível de formações ainda não havia sido realizada, visto que Almeida (1965) e Boggiani (1998) a apresentam somente ao nível de grupo ou em seções geológicas, e os mapeamentos geológicos realizados pela CPRM, na década de 1970, apresentam proposta litoestratigráfica distinta, mantida em algumas sínteses mais recentes (Godói, 2001; Lacerda Filho et al., 2006).

\section{CONTEXTO TECTÔNICO REGIONAL}

A evolução tectônica da Faixa Paraguai está associada à amalgamação final do Gondwana Ocidental, durante o Ediacarano e Cambriano, eventualmente com uma fase rifte no final do Criogeniano. Tohver et al. (2006) confirmam essa asserção por meio de dados paleomagnéticos que indicam idade de 520 Ma para a colisão dos blocos Amazônico - West Africa com blocos menores mais a oeste como o Rio Apa e Pampia.

Considera-se que a Faixa Tucavaca (Litherland et al., 1986), na Bolívia, teve uma evolução sincrônica com a Faixa Paraguai, possivelmente como um aulacógeno, sendo que um modelo de evolução em junção tríplice R-R-R já havia sido anteriormente proposto (Jones, 1985). O Grupo Itapucumi no Paraguai é correlato, em parte, às unidades litoestratigráficas da Faixa Paraguai, com evidências de que possa constituir outra faixa de dobramentos a oeste do bloco Rio Apa, com vergência oposta à da Faixa Paraguai (Boggiani, 1998; Campanha et al., 2010).

Trompette (1994), e Trompette, Alvarenga e Walde (1998), sugerem que a Faixa Paraguai evoluiu como uma bacia de antepaís com relação à cadeia orogênica das faixas 

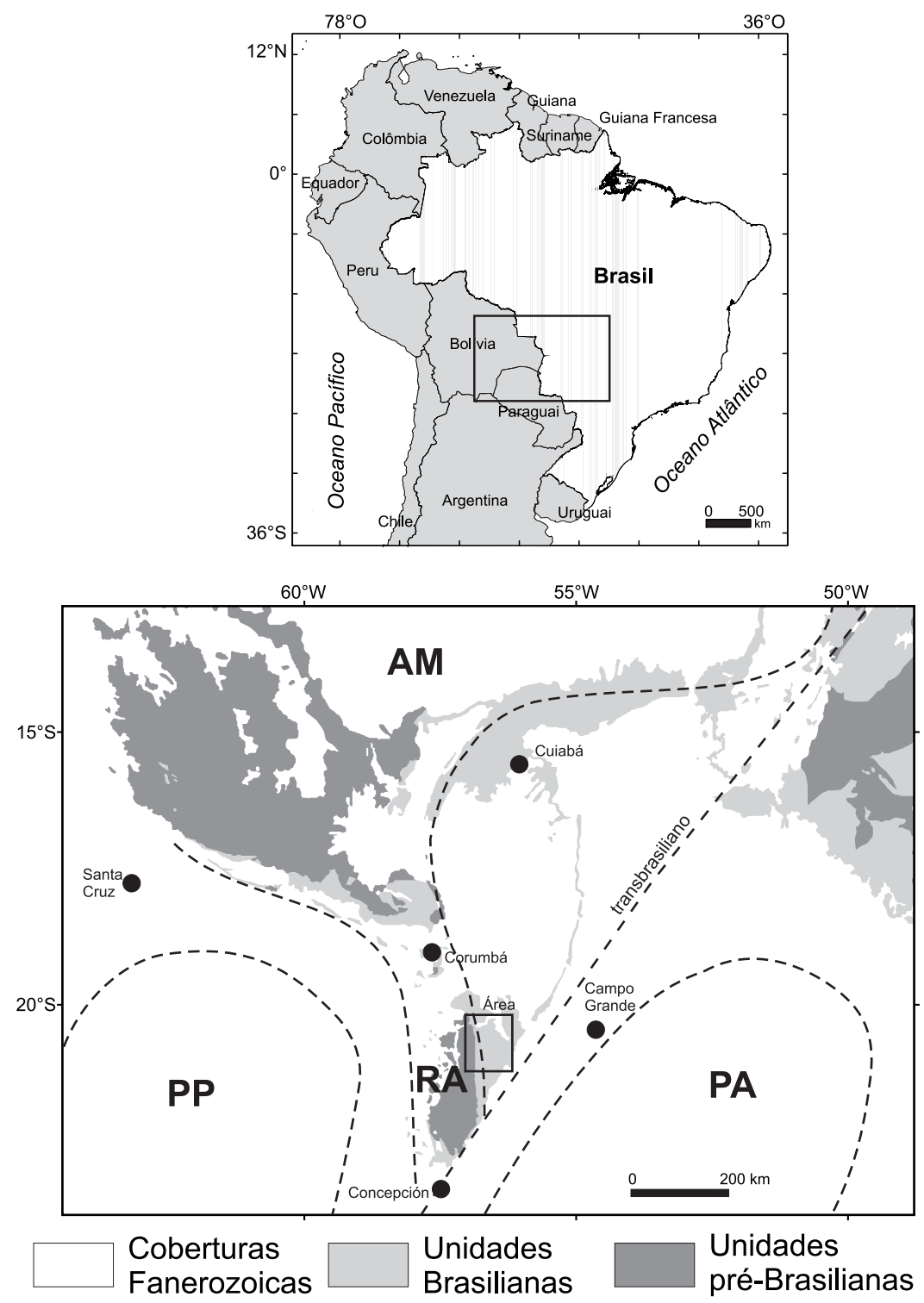

,- - - Limites aproximados Crátons: PP- Pampia AM- Amazônico
Cráton-Faixa Móvel

Figura 1. Contexto tectônico da Faixa Paraguai e localização da área estudada.

Brasília e Ribeira, com uma fase rifte inicial. Outra linha de interpretação postula uma evolução inicial de rifte para margem passiva (Boggiani, 1998; Gaucher et al., 2003). Neste modelo, um oceano deveria existir mais a leste, mas suas evidências estariam encobertas pela bacia sedimentar do Paraná. Woldemichael (2003), baseado em dados magnetotelúricos e gravimétricos, sugere a existência de uma margem colisional entre os crátons do Paranapanema e Rio Apa, o que implicaria na existência de um oceano anterior.
O metamorfismo na Faixa Paraguai cresce de oeste para leste e transformou as rochas pelíticas em filitos e micaxistos de diversos tipos, estes com segregação de veios de quartzo leitosos. O metamorfismo regional no entanto não ultrapassou a fácies xisto-verde, atingindo a leste a zona da biotita (e.g., Almeida, 1965; Alvarenga, 1988; Sá, 2009).

$\mathrm{Na}$ tentativa de melhor definir o zoneamento tectônico que se observa de oeste para leste, a Faixa Paraguai foi diferenciada em duas zonas distintas com direção norte-sul, uma 


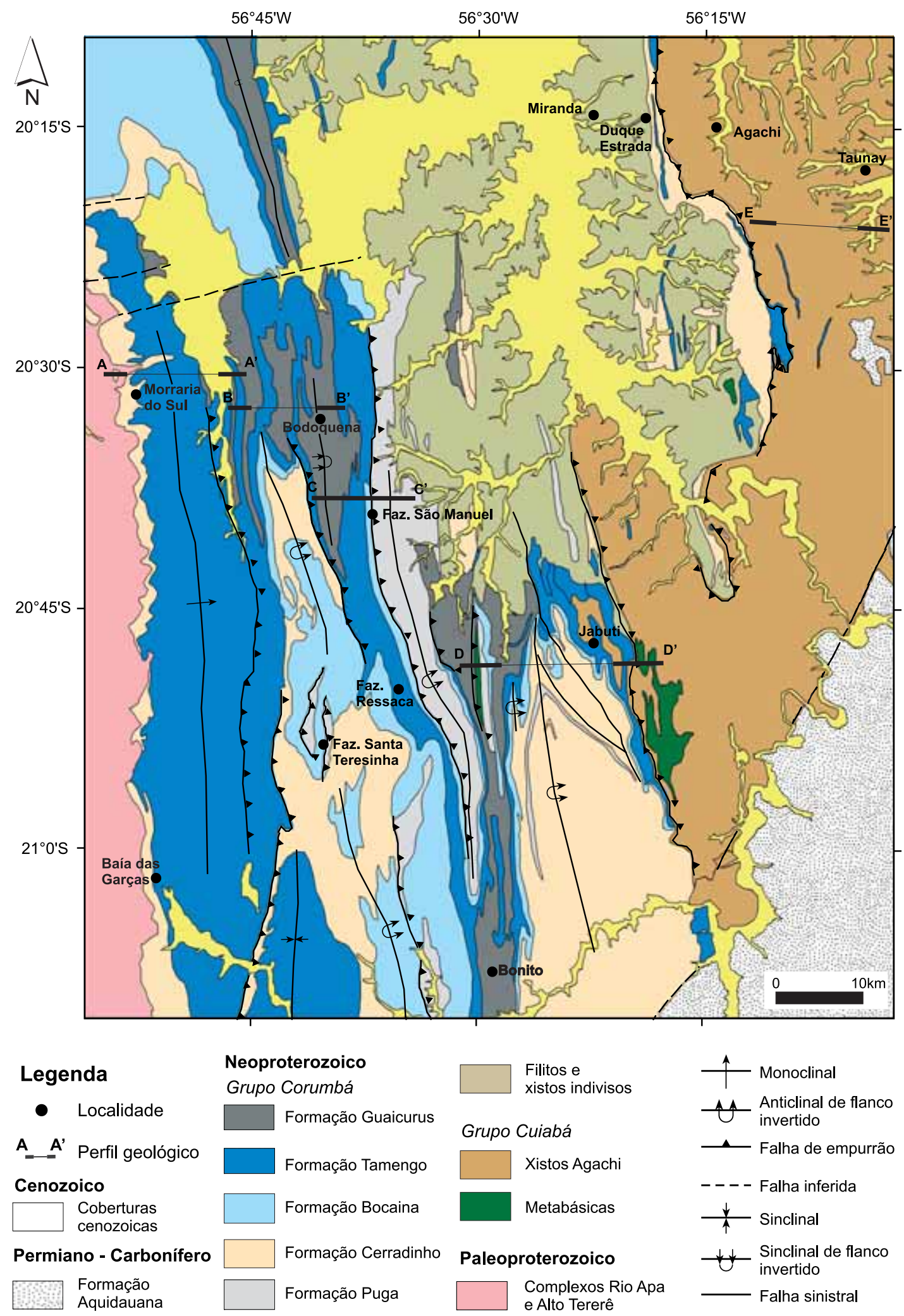

Figura 2. Mapa geológico de parte da Faixa Paraguai meridional, nas regiões da Serra da Bodoquena e depressão do rio Miranda. 

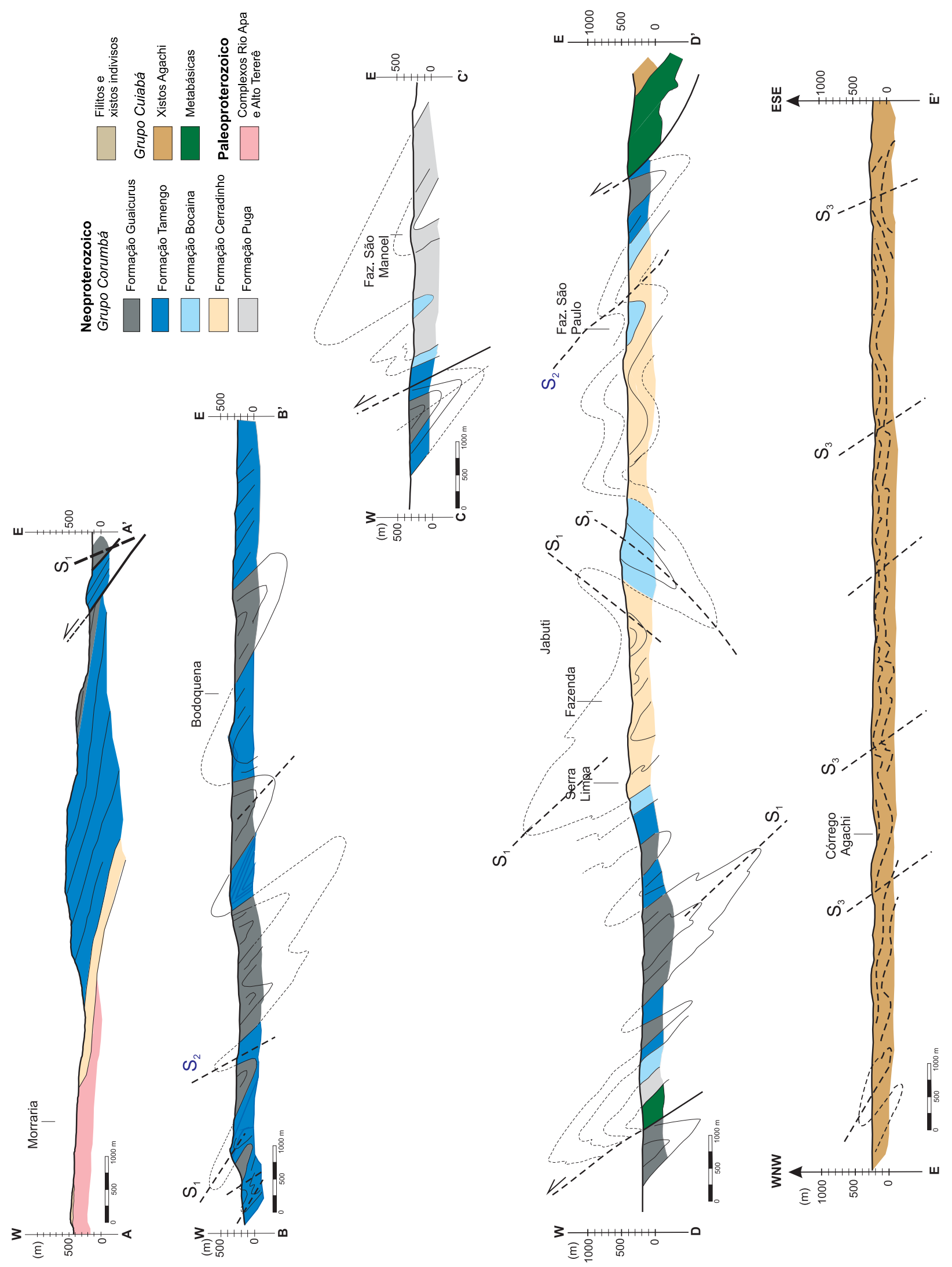

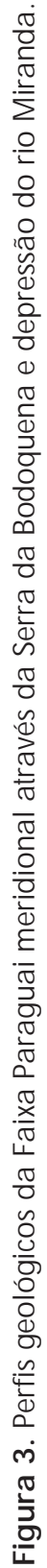


mais ocidental e outra mais oriental, chamadas de Brasilides não metamórficas e Brasilides metamórficas por Almeida (1984), e faixas Externa e Interna por Alvarenga (1988).

Almeida (1968) distinguiu três estádios estruturais na evolução da Faixa Paraguai como um todo, separados por discordâncias regionais e mudanças contrastantes de litologia, associados à zonalidade tectônica, dispostos em longas e estreitas faixas paralelas à borda do cráton.

O estádio mais antigo, registrado no Grupo Cuiabá, seria formado principalmente por rochas pelíticas com caráter de flysch (turbiditos), metamorfizadas na fácies xisto verde, intensamente dobradas, tendo na base camadas de quartzitos e calcários subordinados. $\mathrm{O}$ estádio médio afetaria os diamictitos do Grupo Jangada (atualmente referidos como Formação Puga), recobertos pelas sucessões carbonáticas dos grupos Corumbá (porção meridional da faixa) e Araras (na porção setentrional). O estádio superior encontra-se representado no Grupo Alto Paraguai, ocorrente apenas na porção setentrional, com sedimentação continental "molássica" em sua parte superior.

Alvarenga e Trompette (1992) distinguem na Faixa Paraguai três grandes associações estratigráficas. A unidade inferior apresenta fácies glácio-marinhas, correspondentes na zona externa à Formação Puga, gradando em direção a leste na zona interna para turbiditos com influência glacial, incluídos no Grupo Cuiabá. A unidade inferior é recoberta por unidade carbonática que marca o fim da influência glacial e a subida do nível do mar. Corresponde ao Grupo Araras na porção setentrional da Faixa Paraguai, e ao Grupo Corumbá na porção meridional. A unidade mais superior compreende uma sucessão de rochas siliciclásticas, aflorante apenas na parte norte, definida como Grupo Alto Paraguai.

Alvarenga e Trompette (1993) reconhem na porção setentrional da Faixa Paraguai quatro fases de deformação progressiva, D1 a D4, com aumento da deformação e do metamorfismo da região cratônica em direção a faixa dobrada. As três primeiras fases (D1 a D3) são quase coaxiais com direção NE-SW, enquanto a fase D4 é transversal (NW-SE). A primeira fase D1 é a mais proeminente, e contemporânea com o metamorfismo regional, incluindo dobras fechadas e isoclinais a dobras abertas associadas à clivagem S1, nas áreas internas com nítida vergência em sentido oposto ao cráton. As fases D2 e D3 estão representadas principalmente por uma clivagem de crenulação de caráter local ( $\mathrm{S} 2$ e S3). A fase $\mathrm{D} 4$ é caracterizada por amplos dobramentos regionais. Consideram que a evolução sedimentar e a deformação dessas rochas podem ser interpretadas tanto como resultado de uma orogênese de colisão com o desenvolvimento completo do ciclo de Wilson, ou como o fechamento de um aulacógeno ou rifte intracontinental, possivelmente com reduzida oceanização.
Pimentel et al. (1996) estudando granitos pós-orogênicos de alto K na porção oeste de Goiás, associam esse magmatismo a um evento extensional com soerguimento e denudação regionais, o qual seria sincrônico aos estágios iniciais de sedimentação terrígena e carbonática das faixas Paraguai e Tucavaca, os quais representariam provavelmente riftes relacionados à separação da Laurentia do Gondwana no final do Proterozoico e início do Paleozoico,

Dantas et al. (2009) estudaram as assinaturas isotópicas de Nd da porção setentrional da Faixa Paraguai. Consideram que as sucessões sedimentares inferior e intermediária constituíram uma margem passiva com áreas fontes paleo a mesoproterozoicas, situadas provavelmente no Cráton Amazônico. Já as porções superiores (Grupo Alto Paraguai) representariam sucessões de foreland com áreas fonte neoproterozoicas situadas possivelmente na própria Faixa Paraguai, no arco magmático de Goiás ou na Faixa Brasília.

\section{GEOLOGIA DA FAIXA PARAGUAI MERIDIONAL NA SERRA DA BODOQUENA E DEPRESSÃO DO RIO MIRANDA}

\section{Estratigrafia}

O Grupo Corumbá na região da Serra da Bodoquena inclui, da base para o topo, as formações Cadiueus, Cerradinho, Bocaina, Tamengo e Guaicurus (Almeida, 1965; Boggiani, 1998; Gaucher et al. 2003). A Formação Cadiueus compõe-se por conglomerados e arenitos. A Formação Cerradinho é composta por arenitos, arcósios, dolomitos e pelitos. A Formação Bocaina constitui-se predominantemente por dolomitos com estruturas sedimentares de águas rasas, por vezes com estromatólitos e fosforitos no topo, enquanto que a Formação Tamengo corresponde a calcários escuros e pelitos carbonosos de águas mais profundas. A Formação Guaicurus se expressa por pacote predominantemente pelítico (Figura 4).

A oeste da Serra da Bodoquena, o Grupo Corumbá recobre em discordância rochas do bloco Rio Apa, constituído pelos complexos Rio Apa e Alto Tererê. Na porção centro-leste da Serra da Bodoquena o Grupo Corumbá assenta-se sobre conglomerados, diamictitos e arenitos da Formação Puga. Na baixada do rio Miranda, zona tectonicamente mais deformada, ocorrem xistos e quartzo xistos em geral associados ao Grupo Cuiabá, neste trabalho denominados localmente como Xistos Agachi, colocados tectonicamente sobre as rochas do Grupo Corumbá e Formação Puga.

A Formação Puga constitui-se por conglomerados polimíticos (diamictitos), com matriz mal selecionada, variando de pelítica a arenosa, arcosiana e/ou lítica. Os clastos são de quartzo, quartzitos, gnaisses, granitos, anfibolitos, raramente de filitos e calcários, com dimensões de milimétricas 
0

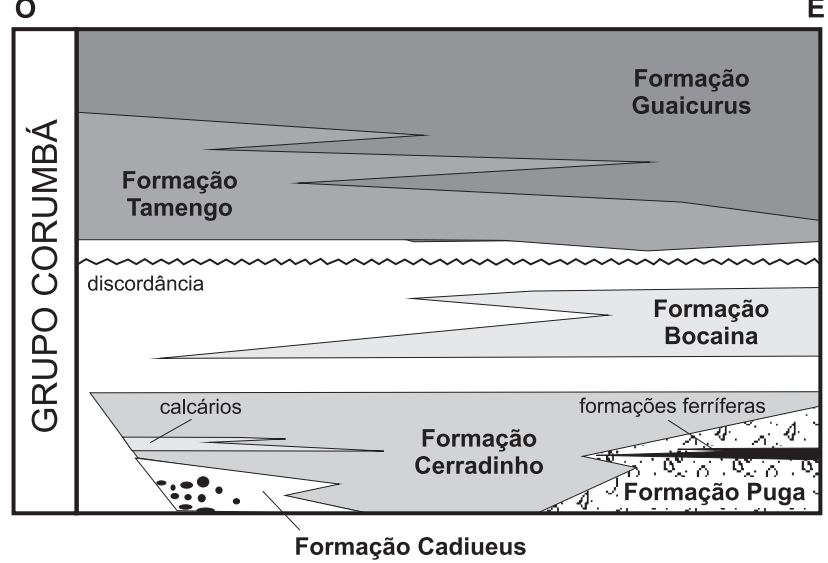

Figura 4. Carta Estratigráfica do Grupo Corumbá e Formação Puga.

a decamétricas. Ocorrem no núcleo de alguns anticlinais ou em lascas de empurrão, como a W e a E da Fazenda Santa Terezinha, a NW e W de Bonito, no Anticlinal Anhumas (Figura 2). Destacam-se os níveis de diamictitos ferruginosos (formação ferrífera), presentes no corpo maior de diamictitos a leste da Serra da Bodoquena (Boggiani et al., 2006; Piacentini et al., 2007; Piacentini, 2008). Em alguns locais observou-se capa de dolomitos laminados avermelhados, assentados diretamente sobre os diamictitos, como nos anticlinais da Fazenda Santa Terezinha e Anhumas (Figura 2).

A Formação Cadiueus (Almeida, 1965) ocorre apenas em faixa estreita na borda oeste da Serra da Bodoquena, a NW de Morraria do Sul (arredores do Posto Indígena Alves de Bastos). Constitui-se por conglomerados e arenitos, que ocupam depressões no paleorelevo ou eventualmente pequenos grábens, sotoposta à Formação Cerradinho.

Na região de Morraria do Sul, a Formação Cerradinho apresenta dois membros distintos, um dolomítico basal, em geral laminado, localmente com estromatólitos, assentado diretamente sobre o embasamento, e outro superior, predominantemente siliciclástico, com arenitos, arcósios, siltitos, dolomitos e folhelhos, em geral avermelhados, com espessura total da ordem de $150 \mathrm{~m}$ (Figura 4).

Não foram observados contatos discordantes entre as formações Puga e Cerradinho. Ao contrário, em alguns locais, como nas proximidades da fazenda Santa Terezinha e a leste da fazenda Ressaca (Figura 2), nota-se a passagem dos diamictitos para arenitos e arcósios com seixos esparsos. No núcleo do anticlinal do Jabuti, mais a $\mathrm{E}$ e NE de Bonito, ocorre expressiva sucessão de metarenitos, metarcósios e metassiltitos, com intercalação de nível de diamictitos, que aqui foi considera-se como correlata à Formação Cerradinho.
A Formação Bocaina é representada por pacotes carbonáticos mais espessos, em geral dolomitos silicosos, brancos e maciços, por vezes oolíticos e com ocorrência de estruturas estromatolíticas. Ocorre tipicamente na região serrana, a W de Bonito (Anhumas, Pedreira Arco-íris e Gruta do Lago Azul), bem como nas fazendas Santa Terezinha, Ressaca e anticlinal do Canastrão. Na região da Fazenda Ressaca ocorrem fosforitos associados à porção superior desta Formação (Boggiani, Fairchild e Coimbra, 1993; Justo, 2000).

Na passagem da Formação Bocaina para a Formação Tamengo ocorre por vezes uma brecha que inclui seixos e blocos angulosos de dolomitos brancos silicosos, e eventualmente de fosforitos, da Formação Bocaina. Esta brecha mostra uma matriz calcária cinza escura típica da Formação Tamengo, sugerindo ser uma brecha basal. O contato brusco mantém-se nas passagens laterais entre as duas unidades.

A Formação Tamengo caracteriza-se por calcários calcíticos cinza escuros a pretos, por vezes sulfetados, com frequentes intercalações de pelitos. Em geral são bem estratificados, mas ocorrem também fácies mais maciças, oolíticas e com estratificações cruzadas da ordem de 0,3 a 1,0 m. Estima-se uma espessura de $550 \mathrm{~m}$ para esta Formação.

A Formação Tamengo recobre diretamente tanto o embasamento a oeste, como as formações Puga, Cerradinho ou Bocaina, sugerindo uma transgressão marinha que recobre indistintamente as unidades mais velhas, com uma discordância erosiva na base (Figura 4).

A passagem da Formação Tamengo para a Formação Guaicurus (superior) dá-se de maneira gradativa, através do incremento da espessura e da quantidade de intercalações pelíticas.

A Formação Guaicurus é constituída por pelitos de coloração cinza esverdeado, aflorantes principalmente no núcleo de sinclinais na região serrana, com lentes e camadas decimétricas de marga e calcário, que desaparecem para o topo. Estima-se espessura aproximada de $250 \mathrm{~m}$ para a formação, sendo sua espessura aparente maior devido à duplicação por dobras e lascas de empurrão.

Nota-se uma maior espessura e representatividade em mapa das formações Puga, Cerradinho e Bocaina na porção centro-oriental da Serra da Bodoquena e na região serrana oriental, comparativamente com a porção ocidental da serra, próximo à sua escarpa, onde estas unidades podem ter espessuras reduzidas ou mesmo não estarem presentes.

Para leste da Serra da Bodoquena, coincidindo aproximadamente com a baixada (depressão periférica) do rio Miranda, ocorrem xistos e quartzo xistos, já na zona da biotita, em geral com abundantes veios de quartzo. A estratificação sedimentar reliquiar é difícil de ser reconhecida e o padrão estrutural é mais complexo. São em geral associados ao Grupo Cuiabá, e neste trabalho denominados 
localmente como Xistos Agachi. Estes xistos aparentam estar colocados tectonicamente sobre metacalcários e metarenitos possivelmente correlatos ao Grupo Corumbá. Inclui-se ai metabasitos, não presentes em outras áreas da Serra da Bodoquena, que podem estar associados ao xistos ou às porções mais basais da Formação Puga (Figuras 2 e 4).

\section{Domínios estruturais}

Em termos tectônicos reconhece-se uma zona de cobertura sedimentar autóctone no domínio ocidental da Serra da Bodoquena, onde sucessões do Grupo Corumbá assentam-se diretamente em discordância sobre os complexos Rio Apa e Alto Tererê (Figura 2). Nele a estratificação sedimentar das unidades do Grupo Corumbá apresenta mergulhos da ordem de $10^{\circ}$ para E e direções em torno de N/S. Na porção leste deste domínio uma clivagem ardosiana pouco proeminente mais empinada passa a seccionar obliquamente a estratificação sedimentar.

Passa-se então a leste para uma região onde as rochas do Grupo Corumbá e da Formação Puga subjacente encontram-se afetadas por um sistema de dobras e empurrões, com típica vergência para W. Corresponde em boa parte à região serrana oriental de Almeida (1965), onde a erosão e os mergulhos mais acentuados das camadas desenvolvem um relevo de serras alongadas na direção NS, tipicamente apalachiano, que ressalta as estruturas geológicas. As dobras apresentam amplitude e comprimento de onda que variam de decimétricos a quilométricos, com planos axiais com mergulhos moderados para E e eixos sub-horizontais que ora caem suavemente para $\mathrm{N}$, ora para S. Desenvolve-se uma clivagem ardosiana com mergulho moderado para E e direção NS, porém com intensidade variável, ocorrendo litotipos desde praticamente indeformados (atestados por ooides da Formação Bocaina e seixos da Formação Puga) até intensamente achatados e estirados, chegando a desenvolver localmente texturas miloníticas. Dobras observadas em escala de afloramento mostram espessamento de charneira, tendendo ao tipo similar. Observa-se um padrão de redobramento em laço em diversos locais, mantendo a atitude de eixos e a vergência.

Visando realizar análise estrutural, a região estudada foi dividida em cinco domínios estruturais maiores, numerados e descritos a seguir de W para E (Figuras 5 a 7).

O domínio I (Figura 5) abrange o embasamento paleoproterozoico a oeste da Serra da Bodoquena (Zona Cristalina Ocidental de Almeida, 1965), constituído pelos complexos Rio Apa e Alto Tererê, recobertos em inconformidade e discordância angular pelas sequências neproterozoicas. Não foi analisado no presente trabalho.

O domínio II (Figura 5) abrange propriamente a Serra da Bodoquena, onde as sucessões neoproterozoicas recobrem em discordância o embasamento, sem deformação dúctil e metamorfismo, sendo que a estratificação sedimentar apresenta um mergulho médio baixo, de poucos graus para leste (Figura 6A). Apenas no seu limite E aparece uma clivagem ardosiana tênue discordante do acamamento quando se passa para o domínio III.

O domínio III (Figura 5) engloba a parte centro-oriental da Serra da Bodoquena e parte da zona serrana oriental (Almeida, 1965). É dominada estruturalmente por dobramentos abertos a isoclinais com eixos sub-horizontais NS e planos axiais mergulhantes para $\mathrm{E}$, por vezes com flancos inversos, associados a falhas de empurrão de direção NS e transporte para W. Ocorre uma clivagem ardosiana $\left(\mathrm{S}_{1}\right)$ plano axial a dobras $\mathrm{D}_{1}$, a qual em certos subdomínios apresenta orientação constante, mas em outros encontra-se afetada por dobramento coaxial $\mathrm{D}_{2}$, configurando um padrão de interferência em laço. Os estereogramas da Figura $6(\mathrm{~B}$ a H) ilustram esse domínio. Lineações de estiramento apresentam atitude de down-dip a direcionais, com indicadores cinemáticos que denotam movimento de empurrão para $\mathrm{W}$ passando a direcionais sinistrais em certas faixas (Figura 6I). Metamorfismo de grau baixo, zona da clorita, é observado.

O domínio IV (Figura 5) abrange o extremo E da região serrana oriental e boa parte da depressão do rio Miranda. Aqui foi analisada essencialmente a região de Jabuti, ainda na região serrana, já que a depressão do rio Miranda apresenta dificuldades quanto a afloramentos e acessos, sendo em grande parte recoberta pela planície aluvial do rio homônimo. A região do Jabuti é dominada por um grande anticlinal de fase $\mathrm{D}_{1}$ orlado por dobras $\mathrm{D}_{1}$ e $\mathrm{D}_{2}$ com padrão de interferência em laço. Esse padrão é bastante semelhante em termos de geometria e orientação ao do domínio III, diferenciando-se pela deformação dúctil mais intensa das rochas. Os estereogramas da Figura 7 (A a E) mostram esse padrão.

O domínio V (Figura 5) situa-se na porção mais oriental da área estudada, entre a depressão do rio Miranda e a Serra de Maracaju, onde as unidades mais antigas encontram-se recobertas pelas rochas sedimentares paleozoicas da Bacia do Paraná, mais especificamente pela Formação Aquidauana. No domínio $\mathrm{V}$ predominam micaxistos e quartzo micaxistos de grau metamórfico baixo, já na zona da biotita, mas sem atingir a zona da granada. A estrutura predominante em escala de afloramento e microscópio é uma clivagem de crenulação milimétrica a submilimétrica $\left(\mathrm{S}_{2}\right)$ associada a bandamento diferenciado, caracterizado pela alternância de filmes de mica e quartzo. Estruturas sedimentares reliquiares em geral não estão mais preservadas, sendo que a estratificação sedimentar pode ser inferida por alternâncias litológicas, estando em geral fortemente transposta. Dobras $\mathrm{D}_{1}$ e $\mathrm{D}_{2}$ são observadas em escala mesoscópica, caracterizadas respectivamente por mostrarem xistosidade $\left(\mathrm{S}_{1}\right)$ e 

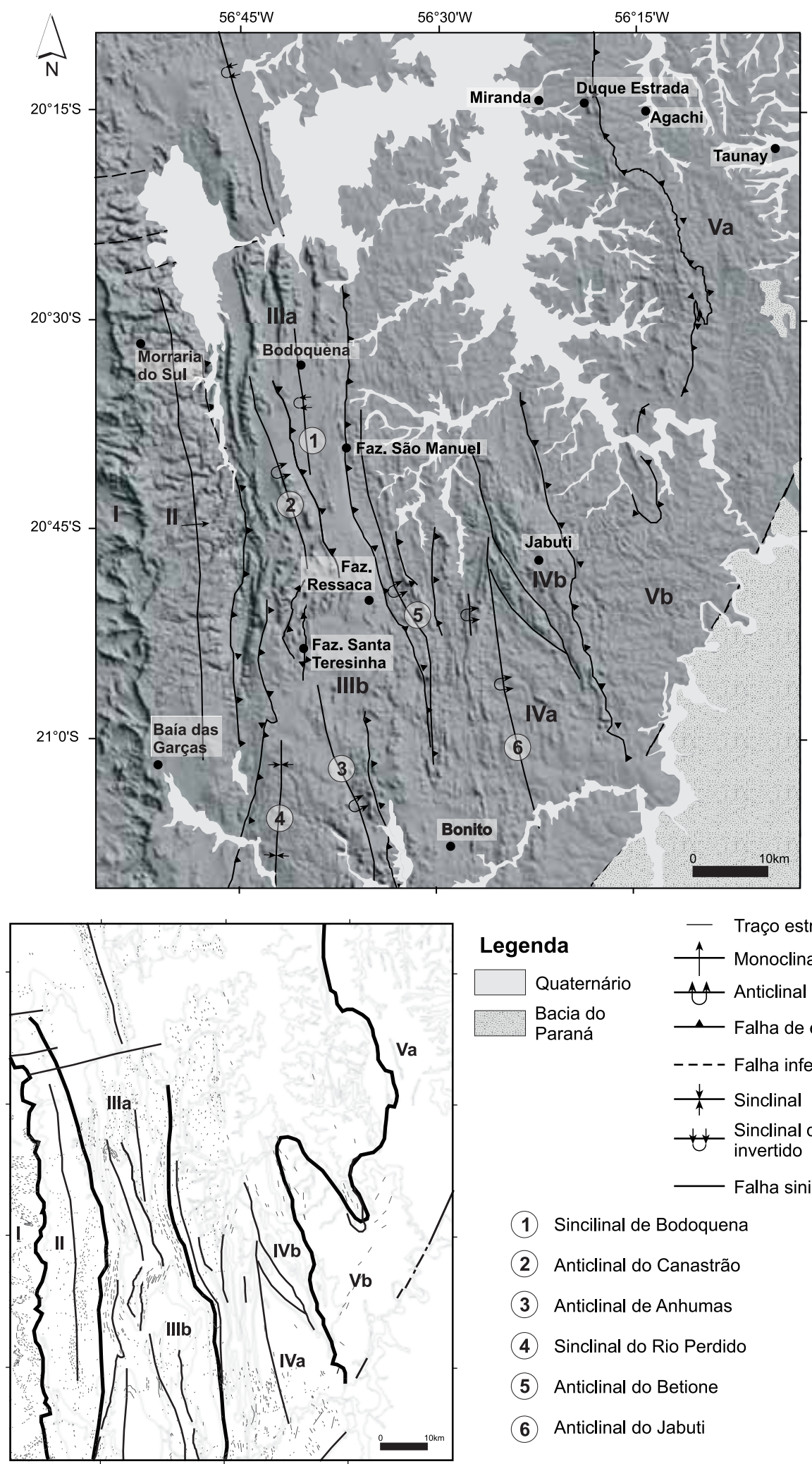

Legenda

- Traço estrutural

$\square$ Quaternário

$\uparrow$ Monoclinal Bacia do
Paraná

U Anticlinal invertido

— Falha de empurrão

- - - Falha inferida

$\frac{\downarrow}{\uparrow}$ Sinclinal

$\forall$ Sinclinal de flanco

Falha sinistral

(1) Sincilinal de Bodoquena

(2) Anticlinal do Canastrão

(3) Anticlinal de Anhumas

(4) Sinclinal do Rio Perdido

(5) Anticlinal do Betione

(6) Anticlinal do Jabuti

Figura 5. Estruturas maiores e domínios estruturais da área estudada, em fundo de relevo sombreado obtido de modelo digital de terreno por SRTM. O s domínios estruturais analisados estão nomeados como I, II, IIla, IIIb, IVa, IVb, Va e Vb (vide texto). 

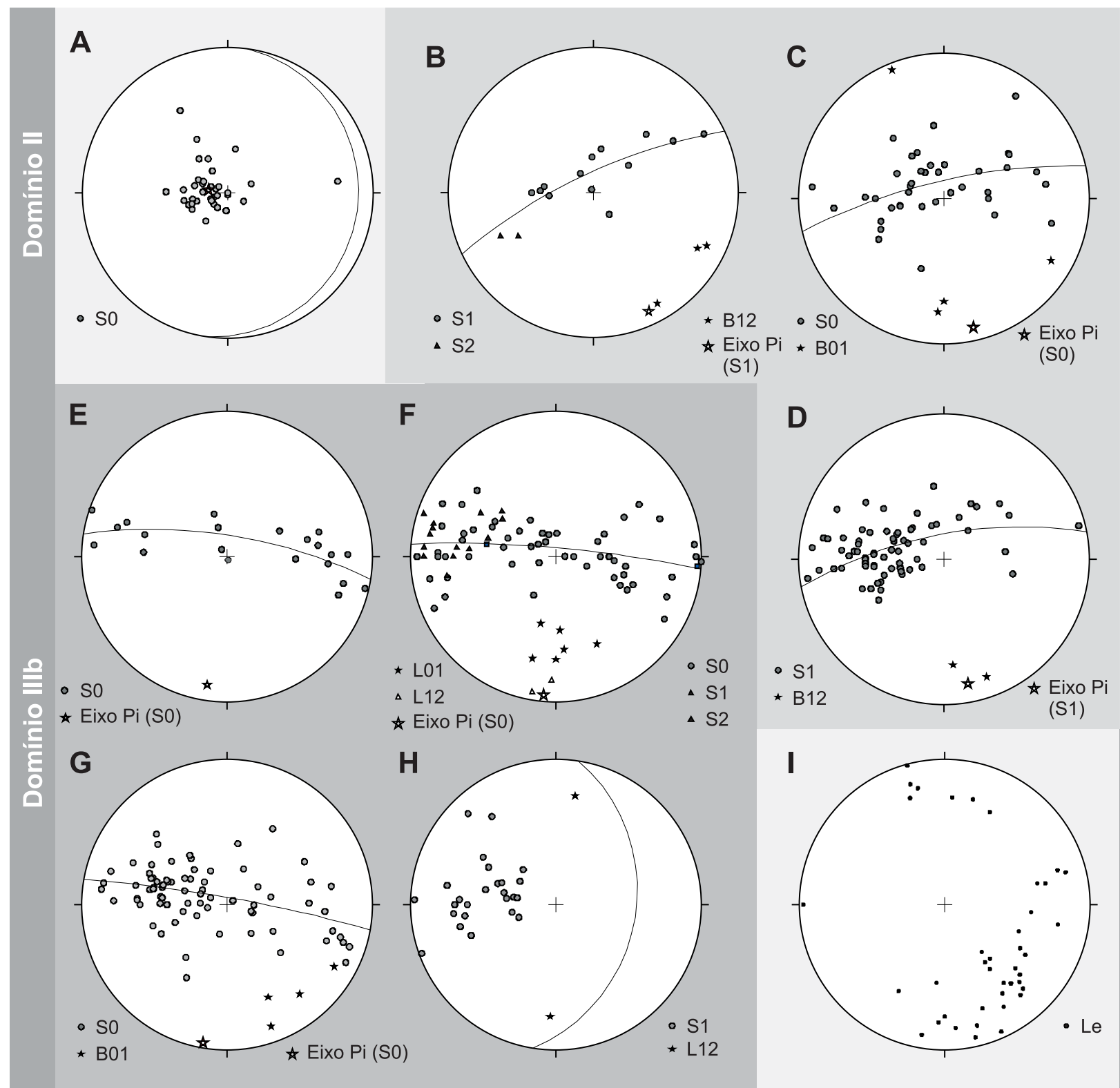

Figura 6. Estereogramas com os dados estruturais levantados nos domínios II e III (rede Schmidt-Lambert, hemisfério inferior), com indicação do melhor plano médio (círculo máximo) e do eixo pi (eixo médio de dobramento), conforme o caso. A. S em todo o domínio II. B. Domínio IIIA, afloramentos FRS75 e FRS76. C. Domínio IIIA, todos os pontos, exceto os afloramentos FRS75 e FRS76. D. Idem. E. Domínio IIIB, afloramento BD030. F. Domínio IIIB, afloramentos BD31 a BD47. G. Domínio IIIB, todos os demais pontos. H. Idem. I. Lineações de estiramento, toda a área.

clivagem de crenulação $\left(\mathrm{S}_{2}\right)$ em posição plano-axial. A foliação predominante $\mathrm{S}_{2}$ mostra em geral mergulhos baixos a moderados, estando afetada por dobras $\mathrm{D}_{3}$ abertas a fechadas, com planos axiais empinados, com mergulho médio maior para leste, e eixos sub-horizontais NS. Em posição plano-axial desenvolve-se por vezes uma clivagem de crenulação espaçada $S_{3}$. Os estereogramas da Figura 7 (F a G) mostram os padrões de orientação das estruturas medidas. Nota-se a coaxialidade entre os eixos e lineações $\mathrm{L}_{01}$, $\mathrm{L}_{12}$ e $\mathrm{L}_{23}$, com atitudes sub-horizontais em torno de NS, e o paralelismo entre a foliação $\mathrm{S}_{3}$ observada no domínio $\mathrm{V}$ com as foliações $\mathrm{S}_{1}$ e $\mathrm{S}_{2}$ observadas dos domínios III e IV. 

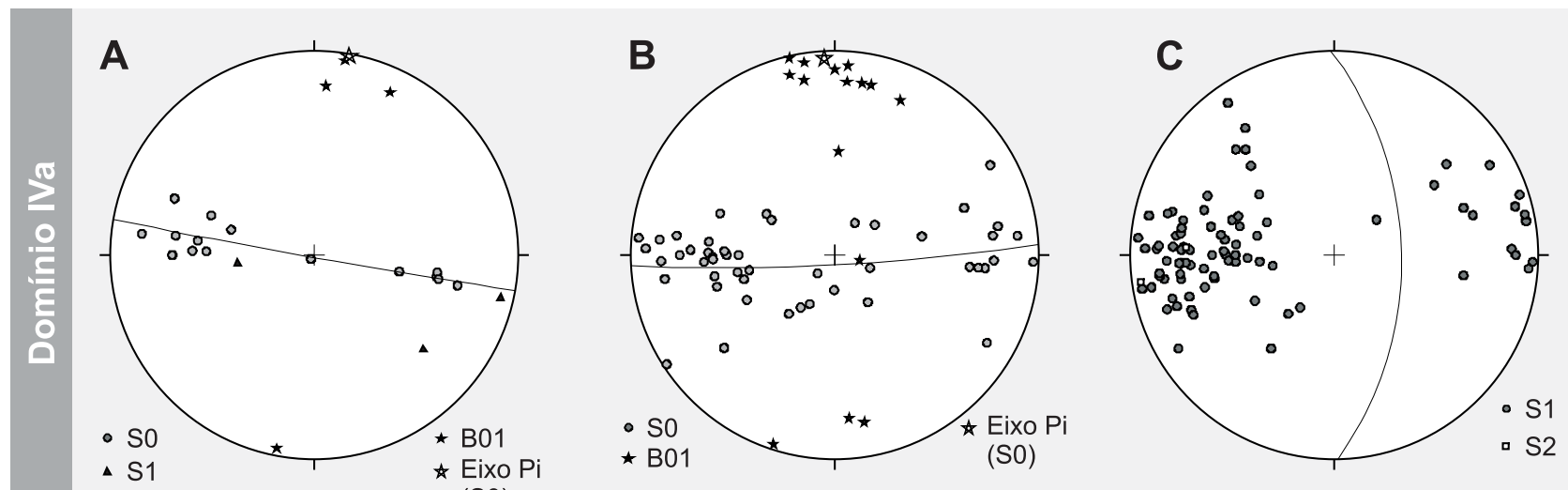

(SO)
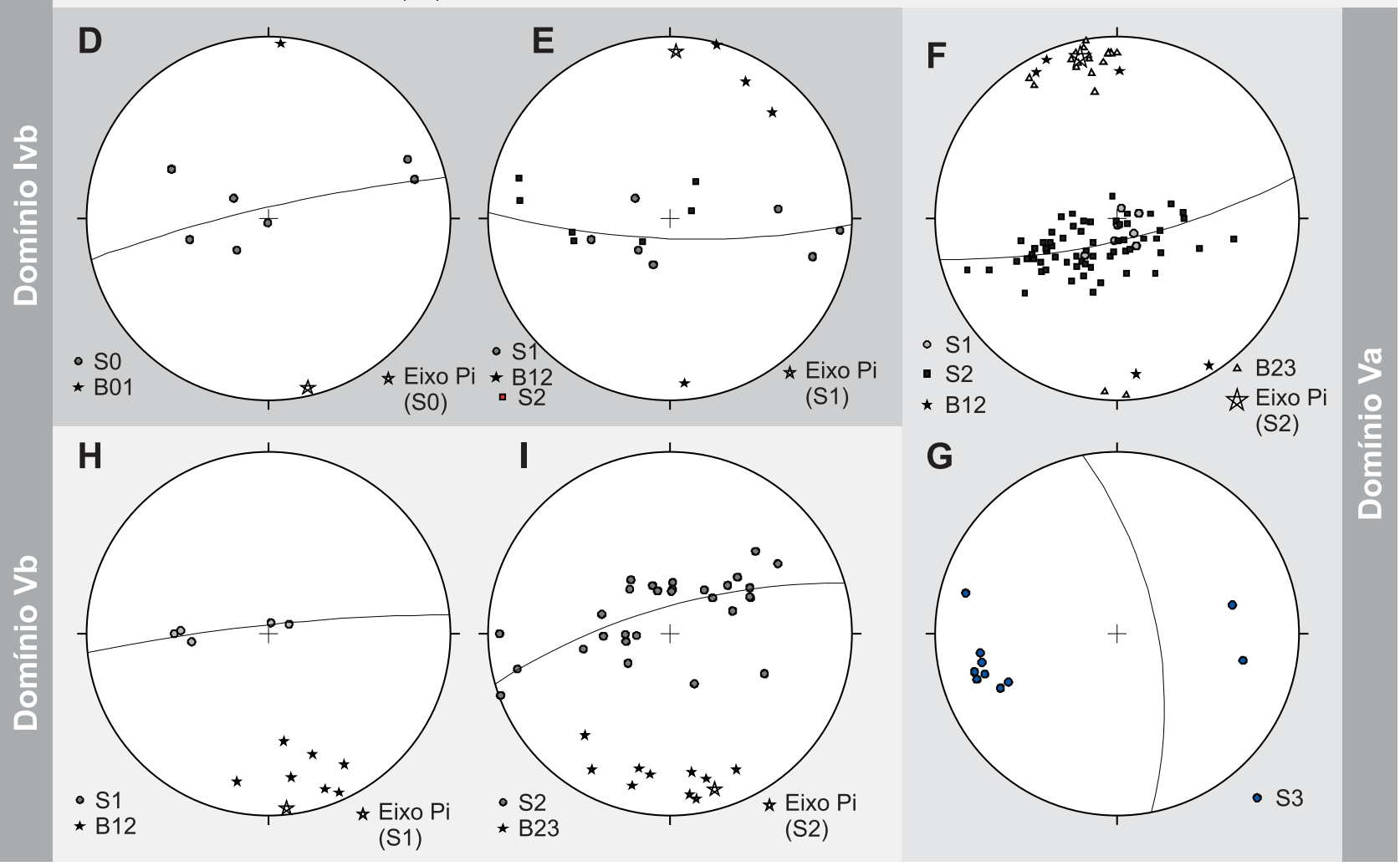

Figura 7. Estereogramas com os dados estruturais levantados nos domínios IV e V (rede Schmidt-Lambert, hemisfério inferior), com indicação do melhor plano médio (círculo máximo) e do eixo pi (eixo médio de dobramento), conforme o caso. A. Domínio IVA, afloramento BD77. B. Domínio IVA, demais pontos. C. Idem. D. e E. Domínio IVB, todos os pontos. F. e G. Domínio VA, todos os pontos. H. e I. Domínio VB, todos os pontos.

\section{Evolução estrutural}

O padrão de lineações de estiramento e de indicadores cinemáticos não aponta para uma colisão ou convergência puramente frontal, mas sugerem algum grau de obliquidade. O padrão predominante de lineações de estiramento down-dip com indicadores cinemáticos indicando empurrão para oeste, coexiste com lineações de estiramento oblíquas a direcionais, com indicadores sinistrais. Esta situação condiz com vetores de convergência da faixa de dobramentos para o bloco rígido do Rio Apa com direções em torno de WNW-ESE. 
A progressão da intensidade e complexidade do padrão deformacional de oeste para leste não ocorre de uma forma absolutamente contínua, mas se da de forma mais ou menos brusca quando se cruza alguns limites tectônicos maiores, em geral falhas de empurrão, que aproximadamente coincidem com os limites de domínios estruturais estabelecidos, e com os limites bacinais mais importantes. Deste modo as maiores espessuras e expressões das formações Cerradinho e Puga, as quais representam o estágio rifte da bacia, bem como da Formação Bocaina, que representa o estágio de mar restrito da mesma, estão na região serrana oriental, aproximadamente limitados pelos empurrões que separam o domínio estrutural II do III, e III do IV. Assim estes empurrões podem coincidir com falhas normais maiores limítrofes dos riftes geradores da bacia, cuja anisotropia mecânica teria condicionada a inversão da bacia no processo colisional.

A progressão do processo deformacional pode ser interpretada de modos diversos. Pode-se pressupor que o front de empurrões migrou de leste para oeste no progredir do evento colisional. A foliação $\mathrm{S}_{1}$ seria gerada inicialmente a leste no domínio $\mathrm{V}$, e o avanço das nappes e empurrões em direção ao antepaís a oeste redobraria as estruturas geradas anteriormente induzindo a migração da deformação para o oeste com o progredir do processo colisional. Assim haveria uma correlação temporal entre a clivagem $\mathrm{S}_{1}$ gerada no limite da área cratônica a leste com a foliação $S_{3}$ gerada nos xistos Agachi a oeste. A coaxialidade entre as gerações de dobramento observadas e a compatibilidade cinemática observadas é explicada neste modelo (Figura 8).

Por outro lado a maior complexidade estrutural nos Xistos Agachi, pode também ser interpretada pela presença de pelo menos uma foliação metamórfica anterior com relação aos domínios mais a oeste. Neste contexto os Xistos Agachi além de mostrar maior grau metamórfico e complexidade estrutural, também seriam mais antigos e colocados tectonicamente por cima das sequências mais novas da Formação Puga e Grupo Corumbá.

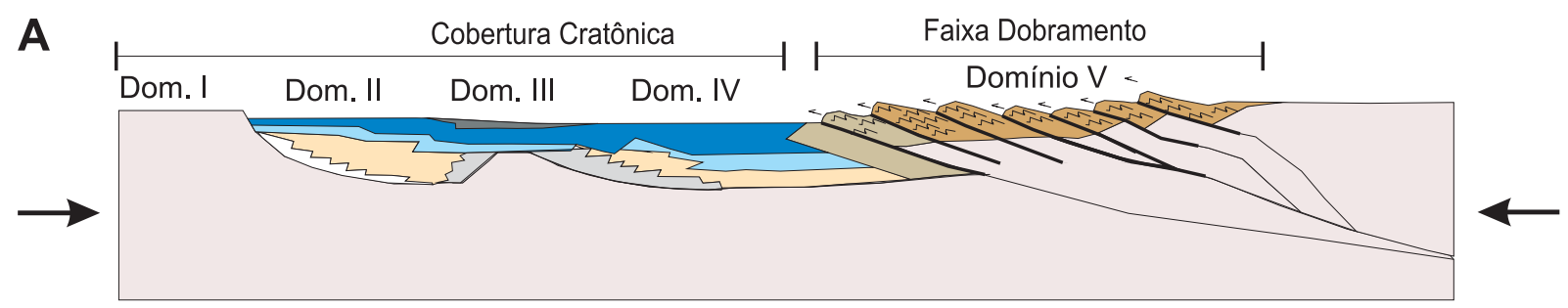

B
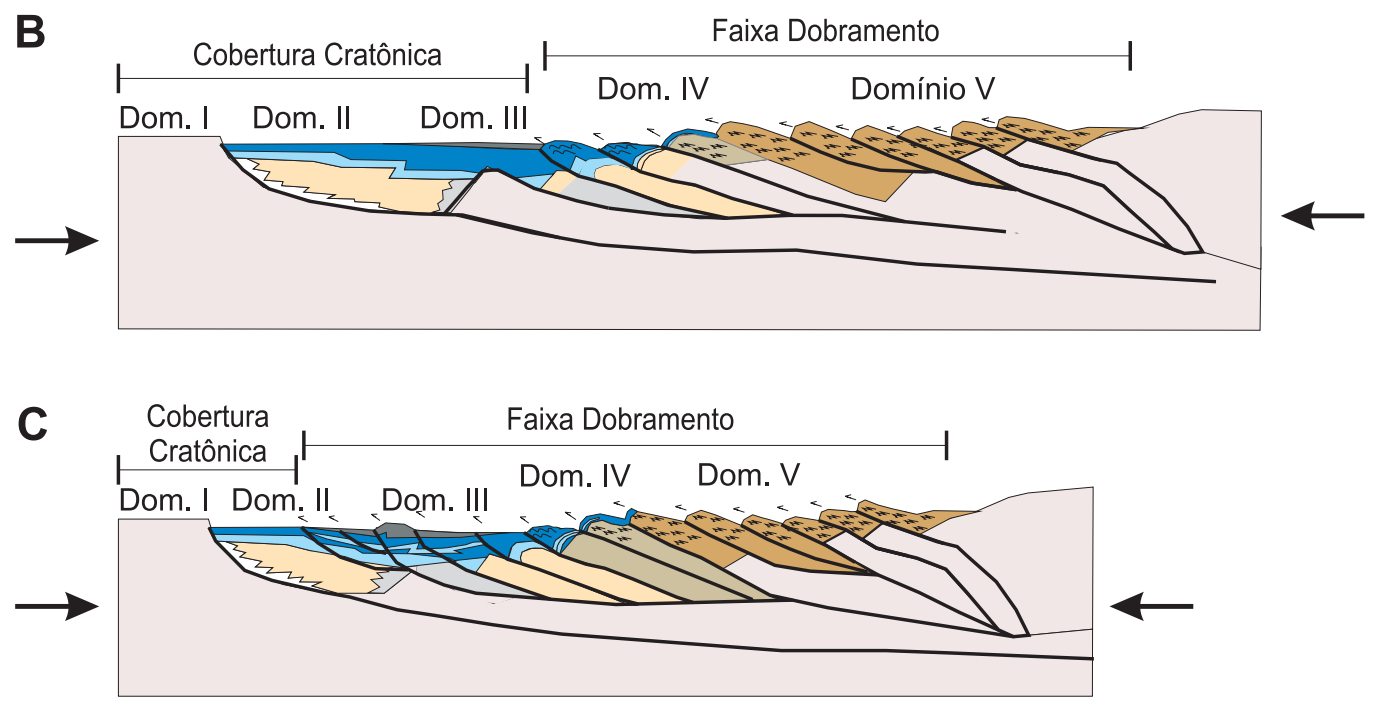

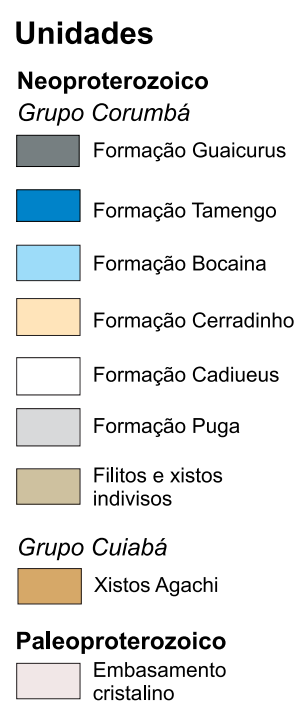

Figura 8. Modelo de evolução estrutural para a Faixa Paraguai na área estudada, mostrando a migração do front deformacional de leste para oeste, em três momentos distintos. 


\section{DISCUSSÃO}

Considera-se aqui que a coluna estratigráfica proposta para a Faixa Paraguai Meridional por Almeida (1965) e Boggiani (1998) seja aplicável para a Serra da Bodoquena, a Zona Serrana Oriental e parte da Depressão do Rio Miranda. O empilhamento proposto pode ser observado em diversos anticlinais e sinclinais ao longo dos perfis levantados.

A subdivisão estratigráfica adotada para o Grupo Corumbá foi estabelecida inicialmente por Almeida (1965), e abandonada em trabalhos posteriores, inclusive pelo próprio autor (Almeida, 1984). Nos trabalhos de Corrêa et al. $(1976,1979)$ e Nogueira et al. (1978) na região da Serra da Bodoquena, as formações superiores do Grupo Corumbá (formações Tamengo e Guaicurus), bem como os conglomerados (diamictitos) da Formação Puga, quando presentes nas porções deformadas da faixa de dobramento, foram inseridas no Grupo Cuiabá, interpretado como mais antigo. No entanto, a aplicação de estudo de fácies sedimentares (Boggiani, 1998; Gaucher et al., 2003) implicou na retomada da estratigrafia original de Almeida (1965), propondo inclusive que parte dos filitos mais a leste correspondessem a fácies distais do Grupo Corumbá, talvez equivalentes à Formação Guaicurus. Boggiani (1998) propõe que este esquema é o que melhor se aplica, dentro de uma evolução de uma bacia rift-to-drift.

Análises de isótopos de $\mathrm{C}$ e $\mathrm{O}$ em metacalcários deformados, considerados, no presente trabalho, como Formação Tamengo (Mina Horii, em Bodoquena, e Mina Calbon, em Miranda) mostram valores de $\delta^{13} \mathrm{C}_{\mathrm{PDB}}(+3 \mathrm{a}+4 \%$ ) semelhantes aos da Formação Tamengo na região de Corumbá (MS), o que reforça o posicionamento estratigráfico aqui adotado (Gaucher et al., 2003; Boggiani et al., 2010).

Idade ediacarana é estabelecida para a deposição da Formação Tamengo pela presença dos fósseis Cloudina e Corumbella, observados na região de Corumbá (Fairchild, 1978; Walde et al., 1982; Hahn et al., 1982; Zaine e Fairchild, 1985, 1987; Hahn e Pflug, 1985; Grotzinger et al., 1995). Esta idade é corroborada pela datação de zircões por SHRIMP em cinzas vulcânicas intercaladas na Formação Tamengo na cidade de Corumbá, que forneceu idade média ${ }^{238} \mathrm{U} /{ }^{206} \mathrm{~Pb}$ de $543 \pm 3 \mathrm{Ma}$ interpretada como idade do vulcanismo e da deposição desses carbonatos (Boggiani et al., 2005; Babinski et al., 2008).

Idade de $645 \pm 14$ Ma foi obtida por isócrona $\mathrm{Rb} / \mathrm{Sr}$ a partir de folhelhos da Formação Cerradinho, Grupo Corumbá, na localidade de Morraria, na Serra da Bodoquena (Oliveira, 2004; Cordani, Oliveira, Boggiani, 2005). Esta idade é possível em termos geológicos já que a Formação Cerradinho está sotoposta às sequências carbonáticas da Formação Tamengo, separada por provável discordância, o que representaria intervalo de tempo de dezenas de milhões de anos entre as unidades basais e superiores do Grupo Corumbá.

O evento glacial representado pelos diamictitos da Formação Puga (Maciel, 1959; Almeida, 1964) foi correlacionado ao Varanger/Marinoan (Alvarenga e Trompette, 1992; Alvarenga et al., 2004; Alvarenga et al., 2009). Sua caracterização e passagem para os cap carbonates pós-glaciais tem sido recentemente estudada por vários autores tanto nas porções meridionais como setentrionais da Faixa Paraguai (Boggiani e Coimbra, 1996; Nogueira et al., 2003; Boggiani et al., 2003; Alvarenga, Santos, Dantas, 2004). As únicas idades geocronológicas disponíveis para a Formação Puga, são as obtidas a partir de datação pelo método SHRIMP de zircões detríticos, obtidos em exposições dessa unidade na Serra da Bodoquena e morro do Puga, entre os quais a idade mais jovem obtida foi de $706 \mathrm{Ma}$ (Babinski et al., 2008).

Apesar da Formação Puga ter sido originalmente definida na porção meridional da Faixa Paraguai, no Morro do Puga (Maciel, 1959), não têm sido observados seixos facetados e/ou estriados nessas exposições, ao contrário do que ocorre na porção setentrional da Faixa. Diante desse quadro, existe a possibilidade dos diamictitos da porção sul não representarem registro glacial e terem se depositado em fluxos gravitacionais associados à abertura do rifte, ao contrário dos diamictitos do norte, originalmente descritos como Formação Jangada (Almeida, 1964).

O Grupo Cuiabá atualmente é uma unidade estratigráfica de definição controvertida na Faixa Paraguai. Tem sido considerada como variação lateral (turbiditos distais) da Formação Puga (Alvarenga e Trompette, 1992). Uma correlação com subdivisões do Grupo Cuiabá na porção setentrional da Faixa (e.g., Tokashiki e Saes, 2008) ainda está por ser feita.

Hasui e Almeida (1970) apresentaram datação radiométrica obtida pelo método $\mathrm{K} / \mathrm{Ar}$ em muscovitas finas recristalizadas de xisto em contato com pegmatito na região entre Miranda e Aquidauna (região de Duque Estrada), a qual forneceu idade de $549 \pm 17 \mathrm{Ma}$, que deve refletir o metamorfismo desses metassedimentos considerados como Grupo Cuiabá.

Na região de Nova Xavantina, no extremo leste da porção setentrional da faixa de dobramentos, sequência metavulcânica-sedimentar, com formações ferríferas associadas, foi descrita, sob a denominação Araés, considerada como pertencente ao Grupo Cuiabá (Pinho, 1990; Martinelli, 1998; Dantas e Martinelli, 2003). Dantas e Martinelli (op. cit.) obtiveram isócrona $\mathrm{Sm} / \mathrm{Nd}$ com idade 570 Ma para amostras da rocha metabásica e tufos, a qual, apesar do grande erro observado, foi interpretada como idade da cristalização. Análise ${ }^{40} \mathrm{Ar} /{ }^{39} \mathrm{Ar}$ de biotitas de duas amostra das rochas metavulvânicas forneceram idades entre 541 e $531 \mathrm{Ma}$, interpretadas como idade do resfriamento após o metamorfismo regional (Geraldes et al., 2008). 
Manzano (2009) discrimina os granitoides intrusivos no Grupo Cuiabá em dois grupos. Um ao norte, com características de magmatismo anorogênico e idades por volta de 504 - 509 Ma (granitos São Vicente, Lajinha e Araguaina). Outro grupo ao sul, com características de magmatismo de arco magmático e idades por volta de 540 - $548 \mathrm{Ma}$ (granitos Taboco, Rio Negro, Coxim e Sonora), obtidas por U/Pb LA-ICPMS. Os corpos do sul tem formas alongadas e estreitas, provavelmente controladas pela "Zona de Cisalhamento Sulmatogrossense", caracterizada por um alinhamento NS. São intrusivos concomitantemente com a fase D2 de deformação dos filitos do Grupo Cuiabá, e afetados por uma folição $\mathrm{S}_{3}$ de direção N - NNE associada a zonas de cisalhamento.

Deste modo os dados disponíveis apontam para uma idade por volta de 540 - 550 Ma para o metamorfismo/resfriamento do Grupo Cuiabá, entendendo-se como pertencentes a esta unidade na porção meridional da Faixa Paraguai os filitos ocorrentes entre a serra de Maracaju e a depressão pantaneira, e os Xistos Agachi considerados neste trabalho. Seus primeiros eventos deformacionais e sua sedimentação seriam mais antigos do que isso. Se aceita a correlação com a Formação Puga, sua deposição seria mais nova que $706 \mathrm{Ma}$.

Sincronicamente com a deformação e metamorfismo do Grupo Cuiabá a leste ter-se-ia a deposição das formações Tamengo e Guaicurus a oeste. Com a evolução do orógeno o front de dobras e empurrões migraria para oeste. Neste contexto a deposição das unidades superiores do Grupo Corumbá (formações Tamengo e Guaicurus) teria ocorrido provavelmente no contexto de uma bacia de antepaís com relação ao orógeno em evolução mais a leste, sendo em seguida afetada pela migração da deformação para oeste (Figura 8).

\section{CONCLUSÕES}

A Faixa Paraguai na região estudada caracteriza-se como um típico fold-and-thrust belt, com linearidade de dobramentos e empurrões de direções meridianas com vergência para oeste em direção à área cratônica representada pelo bloco Rio Apa. O aumento do metamorfismo e da complexidade deformacional de oeste para leste corrobora esta assertiva.

A evolução geológica do cinturão principia por processos de rifteamento provavelmente no final do Criogeniano evoluindo para mar restrito e transgressão marinha até o final do Ediacarano. Neste período, sincronicamente com a deformação e metamorfismo do Grupo Cuiabá a leste, ter-se-ia a deposição das formações Tamengo e Guaicurus a oeste, provavelmente num contexto de bacia de antepaís. O final do processo colisional, responsável pela inversão dessa bacia, com a deformação e metamorfismo associados, ocorreu durante o Cambriano inferior. Magmatismo pós-colisional ocorreu no Cambriano Superior.

O modelo estratigráfico proposto por Almeida (1965), modificado por Boggiani (1998), com o Grupo Corumbá subdivido em cinco formações (Cadiueus, Cerradinho, Bocaina, Tamengo e Guaicurus), mostrou-se aplicável mesmo para as áreas deformadas situadas mais a leste. Considera-se a Formação Puga como correlata às porções basais do Grupo Corumbá (formações Cadiueus e Cerradinho). Para os xistos situados no extremo leste da área, usualmente incluídos no Grupo Cuiabá, é proposto o nome local Xistos Agachi, até que suas relações com o Grupo Corumbá e o restante do Grupo Cuiabá sejam melhor estabelecidas.

São observadas até três fases de dobramento sobrepostas coaxiais, com planos axiais empinados mergulhantes para leste e eixos sub-horizontais de direção em torno de norte / sul, com o desenvolvimento de foliações plano-axiais. Associam-se a sistemas de falhas de empurrão com deslocamento da capa para oeste.Ocorre pelo menos uma fase tardia com dobramentos abertos ortogonal às anteriores. Porém são observadas lineações de estiramento tanto down-dip como oblíquas e direcionais, com indicadores cinemáticos denotando movimentação inversa e/ou sinistral. Isto sugere que a convergência colisional, em direção ao bloco Rio Apa, que deu origem à faixa móvel, não foi completamente frontal, existindo algum grau de obliquidade, com vetores de convergência em torno de WNW-ESE.

O estilo estrutural torna-se progressivamente mais complexo de oeste para leste. A oeste as sucessões sedimentares do Grupo Corumbá estão depositadas em inconformidade sobre as rochas do bloco Rio Apa, com mergulhos suaves para leste, sem o desenvolvimento de foliação tectônica e metamorfismo. A partir do primeiro empurrão no alto rio Salobro desenvolve-se clivagem tectônica nas rochas, passando a ocorrer dobramento aberto a isoclinal, com redobramento local em laço, sempre com vergência para oeste. Na baixada do rio Miranda os Xistos Agachi mostram o estilo estrutural mais complexo, com três fases de dobramento coaxiais, com foliações tectônicas mais intensas, passando para a zona da biotita. Este padrão pode ser explicado pela migração do front deformacional de leste para oeste (Figura 8). Ou alternativamente, os Xistos Agachi poderiam ser mais antigos com pelo menos uma foliação anterior, e jogados tectonicamente por sobre as rochas do Grupo Corumbá e Formação Puga.

É sugestivo que as principais falhas de empurrão coincidam com limites bacinais importantes, onde ocorrem variações de espessura e representatividade das formações basais. Provavelmente os empurrões reativaram as antigas falhas lístricas principais do estágio rifte no processo de inversão da bacia. 


\section{AGRADECIMENTOS}

Os autores agradecem ao Professor Carlos José Souza de Alvarenga e a um relator anônimo pela revisão e valiosas sugestões apresentadas ao texto. Agradecem também aos então alunos de pós-graduação ou graduação Sérgio Willians de Oliveira Rodrigues (atualmente no Serviço Geológico do Brasil), Bernardo Tavares Freitas, Luís Fernando de C. Campanha e Talitha Guerrero Duarte pela participação nos levantamentos de campo. O presente trabalho foi realizado com Auxílio à Pesquisa da FAPESP - Fundação de Amparo à Pesquisa do Estado de São Paulo (Processo 04/012330) e é uma contribuição ao IGCP 478 (Neoproterozoic-Early Palaeozoic Events in southwestern Gondwana).

\section{REFERÊNCIAS}

ALMEIDA, F. F. M. de. Geologia da Serra da Bodoquena (Mato Grosso), Brasil. Boletim da Divisão de Geologia e Mineralogia, v. 219, p. 1- 96, 1965.

ALMEIDA, F. F. M. de. Província Tocantins, setor Sudoeste. In: ALMEIDA, F. F. M. de; HASUI, Y. (Coord.). O Pré-Cambriano do Brasil. São Paulo: Editora Edgard Blücher, 1984. p. 265-281.

ALMEIDA, F. F. M. de. Evolução tectônica do CentroOeste Brasileiro no Proterozóico superior. Anais da Academia Brasileira de Ciências, v. 40, p. 285-296, 1968.

ALMEIDA, F. F. M. de. Glaciação Eocambriana em Mato Grosso. Notas Preliminares e Estudos. Divisão de Geologia e Mineralogia, DNPM, n. 117, p. 1-11, 1964.

ALVARENGA DE, C. J. S. Turbiditos e a glaciação do final do Proterozóico superior no Cinturão Paraguai. Revista Brasileira de Geociências, v. 18, p. 323-327, 1988.

ALVARENGA, C. J. S. DE; SANTOS, R.V.; DANTAS, E. L. C-O-Sr isotopic stratigraphy of cap carbonates overlying Marinoan-age glacial diamictites in the Paraguay Belt, Brazil. Precambrian Research, v. 131, p. 1-21, 2004.

ALVARENGA, C. J. S. de; TROMPETTE, R. Glacially influenced sedimentation in the later Proterozoic of the Paraguay Belt (Mato Grosso, Brazil). Palaeogeography, Palaeoclimatology, Palaeoecology, v. 92, p. 85-105, 1992.

ALVARENGA, C. J. S. de; TROMPETTE, R. Evolução tectônica brasiliana da Faixa Paraguai: a estruturação da região de Cuiabá. Revista Brasileira de Geociências, v. 23, p. 18-30, 1993.
ALVARENGA, C. J. S. de Phénomènes sédimentaires, structuraux et circulation de fluides développés à la transition chaîne-craton. Exemple de chaîne Paraguai d’âge protérozoïque supérieur, Mato Grosso, Brésil. 1990. 177 f. Thèse doct. Univ. Aix-Marseille III, France, 1990.

ALVARENGA, C. J. S. DE; BOGGIANI, P. C.; BABINSKI, M.; DARDENNE, M. A.; FIGUEIREDO, M. F.; SANTOS, R. V.; DANTAS, E. L. The Amazonian Palaeocontinent. In: GAUCHER, C.; SIAL, A. N.; HALVERSON, G. P.; FRIMMEL, H. E. (Ed.). Neoproterozoic-Cambrian tectonics, global change and evolution: a focus on southwestern Gondwana. Amsterdam: Elsevier, 2009. 498 p. (Developments in Precambrian Geology, 16).

BABINSKI, M.; BOGGIANI, P. C.; TRINDADE, R. I. F.; FANNING, M. U-Pb SHRIMP ages on detrital zircons from glaciogenic diamictites of the Puga Formation, Southern Paraguay Belt, Brazil. In: INTERNATIONAL GEOLOGICAL CONGRESS, 33., 2008, Oslo. Abstracts... Oslo: IUGS, 2008. 1 CD-ROM.

BOGGIANI P. C.; BABINSKI, M.; YAMAMOTO, J. K.; FAIRCHILD, T. R.; RICOMINI, C.; DIRATGITCH, A. A.; LIU D. U-Pb SHRIMP investigation of ash beds in the Corumbá Group (Ediacaran), Paraguay Belt, Brazil. In: SYMPOSIUM ON NEOPROTEROZOIC EARLY PALEOZOIC EVENTS IN SOUTHWEATERN GONDWANA, 2., 2005, Windhoek - Namibia. Abstracts... Windhoek - Namibia: IGCP-478, 2005, p. 8-9.

BOGGiAnI, P. C.; COIMBRA, A. M. The Corumbá Group (Central South America) in the context of late Neoproterozoic Global Changes. Anais da Academia Brasileira de Ciências. Resumo das Comunicações, v. 68, n. 4, p. 595-596, 1996.

BOGGIANI, P. C. Ambientes de sedimentação do Grupo Corumbá na região central da Serra da Bodoquena, Mato Grosso do Sul. 1990. 91 f. Dissertação (Mestrado) - Instituto de Geociências da Universidade de São Paulo, São Paulo, 1990.

BogGiAnI, P. C. Análise Estratigráfica da Bacia Corumbá (Neoproterozóico) - Mato Grosso do Sul. 1998. 181 f. Tese (Doutorado) - Instituto de Geociências da Universidade de São Paulo, São Paulo, 1998.

BOGGiAnI, P. C.; FAIRCHILD, T. R.; COIMBRA, A. M. O Grupo Corumbá (Neoproterozóico-Cambriano) na região Central da Serra da Bodoquena, Mato Grosso do 
Sul (Faixa Paraguai). Revista Brasileira de Geociências, v. 23, n. 3, p. 301-305, 1993.

BOGGIANI, P. C.: FERREIRA, V. P.; SIAL, A. N.; BABINSKI, M.; TRINDADE, R. I. F.; ACEÑOLAZA, G.; TOSELLI, A. J.; PARADA, M. A. The cap carbonate of the Puga Hill (Central South America) in the context of the post-Varanger Glaciation. In: SOUTH AMERICAN SYMPOSIUM ON ISOTOPE GEOLOGY, 4., Short Papers... Salvador: CBPM/IRD, 2003. v. 1. p. 324- 327.

BOGGIANI, P. C.; PIACENTINI, T.; FAIRCHILD, T. R.; YAMAMOTO, J. K.; CAMPANHA, G. A. da C.; SÁ, F. R. de; ZUQUIM, M. de P. S. Banded Iron Formation (BIF) associated with glacial sediments of the Puga Formation (Marinoan) in the Serra da Bodoquena (Mato Grosso do Sul, Brazil). In: SYMPOSIUM ON NEOPROTEROZOICEARLY PALEOZOIC EVENTS IN SW-GONDWANA. Expanded Abstracts... Uruguay: IGCP-478, Meeting, Punta del Este 2006. p. 227-229.

BOGGIANI, P.C.; GAUCHER, C.; SIAL, A. N.; BABINSKI, M.; SIMON, C. M.; RICCOMINI, C.; FERREIRA, V. P.; FAIRCHILD, T. R. Chemostratigraphy of the Tamengo Formation (Corumbá Group, Brazil): a contribution to the calibration of the Ediacaran carbon-isotope curve. Precambrian Research, v. 182, n. 4, p. 382-401, 2010.

CAMPANHA, G. A. da C.; WARREN, L.; BOGGIANI, P. C.; GROHMANN, C. H.; CÁCERES, A. A. Structural analysis of the Itapucumi Group in the Vallemi Region, Northern Paraguay: Evidence of a New Brasiliano - PanAfrican Mobile Belt. Journal of South American Earth Sciences, v. 30, n. 1, p. 1-11, 2010.

CORDANI, U. G.; OLIVEIRA, D. M.; BOGGIANI, P. C. Caracterização geoquímica das rochas carbonáticas neoproterozóicas do Mato Grosso do Sul e Paraguai. In: CONGRESSO BRASILEIRO DE GEOQUÍMICA, 10 / SIMPÓSIO DE GEOQUÍMICA DOS PAÍSES DO MERCOSUL, 2., 2005, Porto Galinhas, PE. Anais... Porto de Galinhas- PE, 2005. 1 CD-ROM.

CORRÊA, J. A.; CORREIA FILHO, F. C. L.; SCISLEWSKI, G.; NETO, C.; CAVALLON, L. A.; CERQUEIRA, N. L. S.; NOGUEIRA, V. L. Geologia das regiões centro e oeste de Mato Grosso do Sul. Projeto Bodoquena. Brasília: DNPM, 1979, 111 p. 1 mapa geológico. Escala 1:250.000. Série Geológica Básica n, 3

CORRÊA, J. A.; CORREIA FILHO, F. C. L.; SCISLEWSKI, G.; NETO, C.; CAVALLON, L. A.;
CERQUEIRA, N. L. S.; NOGUEIRA, V. L. Geologia das regiões centro e oeste de Mato Grosso. Projeto Bodoquena. Goiânia: DNPM/CPRM, 1976. Relatório final.

DANTAS, E. L.; MARTINELLI, C. C. Nd isotopes from the Araés Metavocano-sedimentary sequence in the Paraguay Belt, Nova Xavantina, Mato Grosso, Central Brazil. In: SOUTH AMERICAN SYMPOSIUM ON ISOTOPE GEOLOGY, 4., 2003, Salvador. Short Papers... Salvador: CBPM/IRD, 2003. v. 1. p. 168-169.

DANTAS, E. L.; ALVARENGA, C. J. S de; SANTOS, R.V.; PIMENTEL, M. M. Using Nd isotopes to understand the provenance of sedimentary rocks from a continental margin to a foreland basin in the Neoproterozoic Paraguay Belt, Central Brazil. Precambrian Research, v. 170, p. 1-12, 2009.

FAIRCHILD, T. R. Evidências paleontológicas de uma possível idade "ediacariana" ou cambriana inferior, para parte do Grupo Corumbá (Mato Grosso do Sul). In: CONGRESSO BRASILEIRO DE GEOLOGIA, 30., 1978, Recife. Resumo das comunicações... Recife: Sociedade Brasileira de Geologia, 1978. v. 1. p.181.

GAUCHER, C.; BOGGIANI,P.C.; SPRECHMANN, P.; SIAL, A. N.; FAIRCHILD, T.R. Integrated correlation of Vendian to Cambrin Arroyo del Soldado and Corumbá Groups (Uruguay and Brazil): palaeogeographic, palaeoclimatic and palaeobiologic implactions. Precambrian Research, v. 120, n. 3-4, p.241-278, 2003.

GERALDES, M. C.; TASSINARI, C. C. G.; BABINSKI, M.; MARTINELLI, C. D.; YER, S. S.; BARBOZA, E. S.; PINHO, F. E. C.; ONOE, A. T. Isotopic Evidence for the Late Brasiliano (500-550 Ma) Ore-Forming Mineralization of the Araés Gold Deposit, Brazil. International Geology Review, v. 50, p. 177-190, 2008.

GODOI, H. O. Aquidauna. Folha SF.21-X-A. (Estado de Mato Grosso do Sul). Programa Levantamentos Geológicos Básicos do Brasil. Brasília: CPRM, 2001. Escala 1:250.000.

GROTZINGER, J. P., BOWRING, S. A., SAYLOR, B. Z., KAUFMAN, A. J. Biostratigraphic and Geochronologic Constraints on Early Animal Evolution. Science, v. 270, p. 598-604, 1995.

HAHN, G.; HAHN, R.; PFLUG, H. D.; LEONARDOS, O. H.; WALDE, D. A. G. Körpelich erhaltene scyphozoen reste aus dem Jungpräkambrium Brasiliens. Geologica et Paleontologica, v. 16, p. 1-18, 1982. 
HAHN G.; PFLUG H. D. Die Cloudinidae n. fam., Kalk-Rfhren aus dem Vendium und Unter-Kambrium. Senckenbergiana Lethaea, v. 65, p. 413-431, 1985.

HASUI, Y.; ALMEIDA, F. F. M. de Geocronologia do Centro-Oeste Brasileiro. Boletim da Sociedade Brasileira de Geologia, v. 19, n.1, p. 5-2, 1970.

JONES, J. P. The southern border of the Guaporé Shield in western Brazil and Bolívia: an interpretation of its geologic evolution. Precambrian Research, v. 28, p. 111-135, 1985.

JUSTO, L. J. E. C. Fosfato da Serra da Bodoquena - Mato Grosso do Sul. In: Programa de Avaliação GeológicoEconômica de Insumos Minerais para Agricultura no Brasil. Goiânia: CPRM, 2000, 31p. Disponível em: <ftp:// ftp.cprm.gov.br/pub/pdf/recmin/pimainforme2.pdf $>$. Acesso em: 25 fev. 2008.

LACERDA FILHO, J. V. de; BRITO, R. S. C. de; SILVA, M. da G.; OLIVEIRA, C. C. de; MORETON, L. C.; MARTINS, E. G.; LOPES, R. da C.; LIMA, T. M.; LARIZATTI, J. H.; VALENTE, C. R. Geologia e Recursos Minerais do Estado de Mato Grosso do Sul: texto explicativo. Campo Grande: CPRM - Serviço Geológico do Brasil, 2006. 200 p. 1 mapa. Escala 1:1.000.000.

LITHERLAND, M.; ANNELLS, R. N.; APPLETON, J. D.; BERRANGÉ, J. P.; BLOONFIELD, K.; BURTON, C. C. J.; DARBYSHIRE, D. P. F.; FLETCHER, C. J. N.; HAWKINS, M. P.; KLINK, B. A.; LLANOS, A.; MITCHELL, W. I.; O'CONNOR, E. A.; PITFIELD, P. E. J.; POWER, G.; WEEB, $\mathrm{B}$. C. The geology and mineral resources of the Bolivian Precambrian shield. British Geological Survey, London. Overseas Memoir, 9, 1986, 153 p.

MACIEL, P. Tilito Cambriano (?) no Estado de Mato Grosso. Boletim da Sociedade Brasileira de Geologia, v. 81, p. 31-39, 1959.

MANZANO, J. C. Caracterização dos granitóides brasilianos da Faixa de Dobramentos Paraguai, MS e MT. 2009. 99 f. Dissertação (Mestrado) - Instituto de Geociências da UNESP, 2009.

MARTINELLI, C. A. Petrografia, estrutural e fluidos da mineralização aurífera dos Araés-Nova Xavantina- MT. 1998. 183 f. Tese (Doutorado) - Instituto de Geociências da UNESP, 1998.

NOGUEIRA, A. C. R.; RICCOMINI, C.; SIAL, A. N.; MOURA, C. A. V.; FAIRCHILD, T. R. Soft-sediment deformation at the base of the neoproterozoic puga cap carbonate (southwestern amazon craton, brazil): confirmation of rapid icehouse to greenhouse transition in snowball Earth. Geology, v. 31, p. 613-616, 2003.

NOGUEIRA, V. L.; OLIVEIRA, C. C.; FIGUEIREDO, J. A.; CORRÊA FILHO, F. C. L.; SCISLEWSKI, G.; SOUZA, M. R.; MORAES FILHO, J. C. R.; LEITE, E. A.; SOUZA, N. B.; SOUZA, J. O.; CERQUEIRA, N. L. S.; VANDERLEI, A. A.; TAKASCHI, A. T.; ABREU FILHO, W.; ROSITO, J.; OLIVATTI, O.; HAUSEN, J. E. P.; GONÇALVES, G. N. D.; RAMALHO, R.; PEREIRA, L. C. B. Projeto Bonito - Aquidauana. Goiânia: DNPM/ CPRM, 1978. 14 v. Relatório de Arquivo Técnico do DGM, 2744.

OLIVEIRA, D. M. de. Caracterização geoquímica elementar e isotópica de rochas carbonáticas neoproterozóicas: inferências quimioestratigráficas - sequências sedimentares do Mato Grosso do Sul e Paraguai. 2004. Monografia de Trabalho de Formatura, Instituto de Geociências da Universidade de São Paulo, São Paulo, 2004.

PIACENTINI, T. A Formação Ferrífera da Formação Puga: avaliação regional dos recursos da Serra da Bodoquena, MS. 2008. 65 f. Dissertação (Mestrado) Instituto de Geociências, Universidade de São Paulo, São Paulo, 2008.

PIACENTINI, T.; BOGGIANI, P.; YAMAMOTO, J. K.; FREITAS, B. T.; CAMPANHA, G. A. DA C. Formação ferrífera bandada associada à sedimentação glaciogênica da formação Puga (Mariorano) na Serra da Bodoquena, MS. Revista Brasileira de Geociências, v. 37, p. 530-541, 2007.

PIMENTEL, M. M.; FUCK, R. A; ALVARENGA, C. J. S. Post-Brasiliano (Pan-African) high-K granitic magmatism in central Brazil: late precambrian/early Paleozoic extension. Precambrian Research, v. 80, p. 217-238, 1996.

PINHO, F. E. Geoquímica do depósito de ouro de Nova Xavantina - leste do Estado de Mato Grosso. In: CONGRESSO BRASILEIRO DE GEOLOGIA, 36., 1990, Natal. Anais... Natal: SBG, 1990. v. 3. p. 1316-1330.

SÁ, F. R. de Análise Tectônica de parte da Faixa Paraguai, na região da Serra da Bodoquena, entre os municípios de Morraria e Bodoquena, MS. 2005. 40 f. Monografia de Trabalho de Formatura, Instituto de Geociências da Universidade de São Paulo, São Paulo, 2005. 
SÁ, F. R. de Análise tectono-estratigráfica da Faixa Paraguai meridional na Serra da Bodoquena e depressão do rio Miranda. 2009. 86 f. Dissertação (Mestrado) Instituto de Geociências, Universidade de São Paulo, São Paulo, 2009.

SALLUN FILHO, W. Geomorfologia e geoespeleologia do carste da Serra da Bodoquena, MS. 2005. 196 f. Tese (Doutorado) - Instituto de Geociências, Universidade de São Paulo, São Paulo, 2005.

TOHVER, E.; D’AGRELLA-FILHO, M. S.; TRINDADE, R. I. F. Paleomagnetic record of Africa and South America for the 1200-500 Ma interval, and evaluation of Rodinia and Gondwana assemblies. Precambrian Research, v. 147, p. 193 - 222, 2006.

TOKASHIKI, C. DO C.; SAES, G. S. Revisão estratigrafica e faciologia do Grupo Cuiabá no alinhamento Cangas-Poconé, baixada Cuiabana, Mato Grosso. Revista Brasileira de Geociências v. 38, n. 4, p. 661-675, 2008.

TROMPETTE, R. Geology of Western Gondwana (2000500 Ma). Pan-African - Brasiliano aggregation of South America and Africa. Rotterdam: A. A. Balkema, 1994. 350 p.

TROMPETTE, R.; ALVARENGA, C. J. S., WALDE, D. Geological evolution of the Neoproterozoic Corumbá graben system (Brazil). Depositional context of the stratified Fe and Mn ores of the Jacadigo Group. Journal of South American Earth Sciences, v. 11, n. 6, p. 587-597, 1998.

WALDE, D. H. G.; LEONARDOS, O. H.; HAHN, G.; HAHN, R.; PFLUG, H. The first Precambrian megafossil from South America, Corumbella werneri. Anais da Academia Brasileira de Ciências, v. 54, n. 2, p. 461, 1982.

WOLDEMICHAEL, S. F. Estruturas geoelétricas crustais da bacia do Pantanal e Faixa Paraguai: implicações tectônicas. 2003. 189 f. (Tese Doutorado) - Instituto de Astronomia, Geofísica e Ciências Atmosféricas, Universidade de São Paulo, São Paulo, 2003.

ZAINE, M. F.; FAIRCHILD, F. R. Comparison of Aulophycus lucianoi, Beurlen \& Sommer from Ladário (MS) and the genus Cloudina, Germs, Ediacarian of Namíbia. Anais de Academia Brasileira de Ciências, Resumo das Comunicações, v. 57, n. 1, p. 130, 1985.

ZAINE, M. F.; FAIRCHILD, T. R. Novas considerações sobre os fósseis da Formação Tamengo, Grupo Corumbá, SW Brasil. In: CONGRESSO BRASILEIRO DE
PALEONTOLOGIA, 10., 1987, Rio de Janeiro. Resumo das Comunicações... Rio de Janeiro: Sociedade Brasileira de Paleontologia, 1987, p. 54.

ZUQUIM, M. P. S. Evolução tectônica de um segmento da Faixa Paraguai meridional - área Alto Salobra Fazenda Palmares do Peixe (MS). 2005. 45 f. Monografia de Formatura, Instituto de Geociências da Universidade de São Paulo, 2005. 